\title{
THE MATHEMATICAL ASSOCIATION
}

The fundamental aim of the Mathematical Association is to promote good methods of mathematical teaching. A member receives each issue of the Mathematical Gazette and/or Mathematics in School (according to the class of membership chosen), together with Newsletters. Reports are published from time to time and these are normally available to members at a reduced rate. Those interested in becoming members should contact MA Headquarters for information and application forms. The address of the Association Headquarters is 259 London Road, Leicester LE2 3BE, UK (telephone 0116221 0013). The Association should be notified of any change of address. If copies of the Association periodicals fail to reach a member through lack of such notification, duplicate copies can only be supplied at the published price. If change of address is due to a change of appointment, the Association will be glad to be informed. Subscriptions should be submitted to the Treasurer via Headquarters. Correspondence relating to Teaching Committee should be addressed to Dr Chris Pritchard. The Association's Library is housed in the University Library, Leicester.

Views expressed in the Mathematical Gazette by authors or advertisers are not necessarily those of the Association.

\section{THE MATHEMATICAL GAZETTE}

Editor:

Dr Gerry Leversha, 15 Maunder Road,

Hanwell,

London W7 3PN

g.leversha@btinternet.com

Production Editor:

Mr Bill Richardson,

Kintail,

Longmorn,

Elgin IV30 8RJ

W.P.Richardson@open.ac.uk
Problem Corner:

Mr Nick Lord,

Tonbridge School,

Tonbridge,

Kent TN9 1JP

njl@tonbridge-school.org

Reviews Editor:

Mathematical Gazette Reviews, 259 London Road,

Leicester

LE2 3BE

gazette-reviews@m-a.org.uk

Potential advertisers should send an e-mail to: advertisingcontroller@m-a.org.uk Material for publication should be sent to the Editor.

Books for review should be sent to MA Headquarters.

Advice to authors of notes and articles.

Study the format of articles in the Gazette. Please note the format for references, which should be listed in their order of appearance in an article. MSS may be submitted electronically, preferably in pdf format, or, if sent by post, should be typed and two copies included. (Mathematical expressions may be hand written.) Please send by e-mail not on floppy discs. This edition of the Gazette was produced on an Acorn machine using TechWriter and Draw. 


\section{CONTENTS (continued)}

\section{Notes 97.01 to 97.16 (continued)}

Trigonometry of The Gold-Bug

Erik Talvila

Four methods for a trigonometric integral

Graham Jameson and

Timothy P. Jameson

Interesting bilateral series generalising a

Thomas Osler and

result of Euler

Cory Wright

The devil's series - Did it fool Euler?

Thomas Osler and

Steven Donahue

Continuous functions that are not

Graham Jameson

differentiable anywhere

The rational distance problem for polygons

Roy Barbara

Using Taylor's formula to compare

Jim Farmer

compound and simple interest

A circular locus

Shailesh Shirali

The area of a generalised arbelos

Hiroshi Okumura

Iterating to find sines and cosines

Norman Routledge

Probability analysis for rolls of a square

Carl Mungan and

\section{Teaching Notes}

Mental mathematics for multiples of $\pi$

Trevor Lipscombe

Why the path of quickest descent is not a

Nick Lord

straight line

Fortuitous functions

Chris Little

Feedback

Problem Corner

Nick Lord

Student Problems

Stan Dolan

Reviews 


\section{CONTENTS}

\section{Articles}

Integer sequences that behave as

A. S. di Domenico

Fibonacci-Lucas pairs

Dürer's magic tesseract

Anthony Sudbery

Slide rules, nomograms and additive functions David Hopkins

Pell Walks

Tom Koshy

Composition of polynomials

B. Sury

A generalisation of Archimedes' method

Christof Kirfel

A direct derivation of the Catalan formula

Gerry Leversha

Paradoxical Euler: Integrating by

Andrew Fabian and

Differentiating

Hieu D Nguyen

On proving certain optimisation theorems

I. Grattan-Guinness

in plane geometry

How many deadends in a derangement?

Barry Lewis

Frieze groups, cylinders, and quotient groups Alan Beardon

Matter for Debate

Mathematics, a third way

Christopher Ormell

Notes 97.01 to 97.16

Power solutions of some Diophantine equations

Drago Bajc

Solutions to $\phi(m)=k$ ! and $\sigma(n)=k$ !

Peter Shiu

Insert a root to crack the cubic

R. G. Kulkarni

The solution of quintic equations

R. G. Kulkarni

Two proofs without words

Munir Mahmood and Ibtihal Mahmood

(The contents are continued inside the back cover.)

Typeset by Bill Richardson

Printed in Great Britain by 4word Ltd, Bristol

ISSN 0025-5572 